Rev. Bras. Saúde Prod. Anim., Salvador, v.15, n.2, p.450-458 abr./jun., 2014 http://www.rbspa.ufba.br ISSN 15199940

\title{
Filés de tambacu submetidos a salga seca e salga úmida
}

\author{
Tambacu submitted fillets dry salting and salting
}

\author{
NATES, Vanessa Aparecida ${ }^{1}$; FERREIRA, Milena Wolff ${ }^{*}$; TRINDADE, Carolina \\ Santos Pereira Cardoso ${ }^{2}$; SANTOS, Ricardo Martins ${ }^{1}$; SILVA, Tâmiris Aparecida dos \\ Santos ${ }^{1}$; VALADARES, Raíssa Santana Silva ${ }^{1}$
}

\begin{abstract}
${ }^{1}$ Universidade Católica Dom Bosco, Zootecnia, Campo Grande, Mato Grosso do Sul, Brasil.
${ }^{2}$ Universidade Federal do Mato Grosso do Sul, Departamento de Zootecnia, Campo Grande, Mato Grosso do Sul, Brasil.

*Endereço para correspondência: milena_wolff@ibest.com.br
\end{abstract}

\section{RESUMO}

Vários estudos demonstram que a utilização da salga como método para conservação, principalmente para pescado, tem-se mostrado eficiente e de baixo custo. Com base neste cenário, o objetivo geral do presente projeto é analisar as características higiênico-sanitárias de filés de tambacu submetidos a dois processos de salga: úmida e seca. Após processamento foram avaliados parâmetros microbiológicos, atividade da água e cor, a partir do experimento realizado na Universidade Católica Dom Bosco. Os filés de tambacu utilizados foram submetidos a salga seca utilizando $2 \mathrm{~kg}$ de sal e, salga úmida na proporção de $30 \%$, com relação ao peso inicial dos produtos, ambos permaneceram em tratamento por 07 dias. Após salga foram acondicionados em estufa com ventilação forçada a $40^{\circ} \mathrm{C}$. Os filés da salga seca permaneceram em estufa por 48 horas e os submetidos a salga úmida permaneceu por 72 horas para secagem do produto. Em análises microbiológicas foi feito $o$ teste para Staphylococcus e Salmonella que são os principais contaminantes de produtos alimentares e os resultados demonstraram-se muito abaixo da regulamentação da ANVISA, o que garante as condições higiênico-sanitárias satisfatórias. E a avaliação de cor e atividade de água confirmam essa característica do pescado processado, uma vez que apresentou baixa atividade de água comparada à necessidade mínima para proliferação dos principais patógenos e coloração característica do processamento.

Palavras-chave: atividade de água, cor, Salmonella, Staphylococcus

\section{SUMMARY}

Several studies have shown that the use of salting as a method for preservation, particularly for fish, has proven efficient and cost. Based on this scenario, the overall goal of this project is to analyze the hygienic-sanitary characteristics of fillets tambacu subjected to two curing processes: wet and dry. After processing microbiological parameters, water activity and color, from the experiment conducted at Don Bosco Catholic University were evaluated. The fillets used tambacu underwent dry salting using $2 \mathrm{~kg}$ of salt and damp in the proportion of $30 \%$ with respect to the initial weight of the products, both remained in treatment for 07 days salting. After salting were placed in an oven with forced air at $40^{\circ} \mathrm{C}$. The steaks dry salting remained in the greenhouse for 48 hours and subjected to salting remained for 72 hours for drying. In microbiological testing was done testing for Salmonella and Staphylococcus are the main contaminants of food products and the results are shown far below the regulation of ANVISA, which guarantees the satisfactory sanitary conditions. And the evaluation of color and water activity confirm this characteristic of processed fish, since it had low water activity compared to the minimum requirement for the proliferation of pathogens and main characteristic color processing.

Keywords: color, Salmonella, Staphylococcus, water activity 


\section{INTRODUÇ̃̃̃O}

O Tambacu é um peixe hibrido obtido do cruzamento entre o Pacu (Piaractus mesopotamicus) e o Tambaqui (Colossoma macropomum). Possui uma importância econômica na aquicultura brasileira, apreciado como peixe esportivo e para a piscicultura, devido ao rápido crescimento, ganho de peso e apresentar menores índices de gordura (MARTINS et. al., 2002).

Dentre as formas de processamento, a salga da carne é uma das mais antigas práticas para conservação do alimento, além de ser um processo simples, de fácil elaboração e baixo custo (PEREZ et al., 2007). A salga tem como objetivo a conservação da carne de pescado a partir da retirada de umidade do tecido, seguido paralelamente pela entrada de sal, diminuindo assim a atividade de água e criando condições impróprias para o desenvolvimento microbiano. Para garantir melhor conservação, ao final do processamento, o produto é submetido a processos complementares, como secagem, refrigeração ou defumação (BOTELHO \& NORT, 1972).

Existem dois métodos principais de salga: salga seca e úmida. Na salga seca o peixe é salgado na proporção de $30 \%$ de cloreto de sódio em relação ao peso da matéria prima eviscerada, espalmada em forma de filés ou mantas e o sal fino é colocado sobre o peixe, onde se dissolve formando uma solução concentrada, protegendo da deterioração da proteína desde o início do processo. No entanto, o pescado é mais susceptível a oxidação lipídica com o emprego desta técnica dado o contato do oxigênio com o produto (OGAWA, 1999). A penetração do sal não é homogênea e a forte desidratação produz uma grande desnaturação, tendo como consequência uma aparência desagradável e um baixo rendimento do produto (NOGUCHI, 1972).

A salga úmida é semelhante a seca, com a diferença que a matéria prima é imersa em salmoura a uma proporção de $30 \%$ do peso inicial (SANCHEZ, 1965). A solução saturada de sal permanece no recipiente que contém o peixe o que garante uma baixa concentração de oxigênio no meio, protegendo a gordura do processo de oxidação (CARDOSO, 2003), e a desidratação da carne do peixe é moderada, evitando a aparência desagradável proporcionada na salga seca.

$\mathrm{O}$ presente trabalho busca confirmar a ação benéfica da utilização do sal para conservação de alimentos, utilizando-se da salga seca e úmida, uma técnica barata, que garante condições higiênicosanitárias satisfatórias segundo a regulamentação (ANVISA). Neste contexto objetivou-se avaliar a presença de Salmonella e Staphylococcus, atividade de água e cor de filés de tambacus submetidos a salga seca e úmida durante 60 dias de armazenamento.

\section{MATERIAL E MÉTODOS}

Os Tambacus (híbrido Pacu $\mathrm{x}$ Tambaqui) foram criados em tanque escavado no período de janeiro a setembro de 2012. Neste período foram monitorados parâmetros de qualidade de água, sendo a temperatura média da água de $24^{\circ} \mathrm{C}, \mathrm{o} \mathrm{pH} 6,8$, o oxigênio $4,5 \mathrm{mg} / \mathrm{L}$, e a transparência $65 \mathrm{~cm}$. Os peixes foram alimentados com ração comercial, contendo $36 \%$ de proteína digestível e $3.200 \mathrm{Kcal} / \mathrm{kg}$ de energia digestível na fase inicial, até atingirem 50 gramas de peso vivo, $32 \%$ de proteína digestível e $3.000 \mathrm{Kcal} / \mathrm{kg}$ de 
energia digestível na fase de crescimento (até 150 gramas) e $28 \%$ de proteína digestível e $3.000 \mathrm{Kcal} / \mathrm{kg}$ de energia digestível na fase de terminação.

Ao final do período de cultivo e após 24 horas de jejum, 20 peixes foram despescados aleatoriamente com auxílio de rede de arraste. $\mathrm{O}$ abate $\mathrm{e}$ insensibilização foram feitos com choque térmico em uma mistura de água mais gelo, proporcionando uma temperatura próxima a $0^{\circ} \mathrm{C}$. Logo após, foram eviscerados e lavados com água clorada (05ppm). Em seguida, os peixes foram filetados, por uma única pessoa, para obtenção de 20 amostras.

Os filés foram submetidos ao processo de salga seca e úmida, por um período de 07 dias, durante esse período os mesmos ficaram imersos na solução salina (salga úmida) e com a presença de sal fino nas superfícies filetadas (salga seca). Para salga úmida (salga em salmoura saturada) foram utilizados 20 filés de tambacu pesando em média $785 \mathrm{~g}+87 \mathrm{~g}$, e, para a salga seca, 20 filés pesando em média $659 \mathrm{~g}+48 \mathrm{~g}$. Os filés foram salgados uma única vez na proporção de $30 \%$ de sal em relação ao peso inicial. No processamento dos filés, em ambas as salgas, utilizou-se sal fino. $\mathrm{O}$ delineamento do experimento foi inteiramente ao acaso com dois tratamentos e vinte repetições, sendo cada filé considerado como uma parcela experimental.

Após o processo de salga, que durou 07 dias, para reduzir o teor de umidade a níveis adequados para conservação dos produtos (em torno de $45 \%$ de umidade conforme FERREIRA et al., 2002), os filés foram dispostos em bandejas, umas para cada tratamento e estas foram acondicionadas sobre grades em estufa com ventilação forçada a $40^{\circ} \mathrm{C}$. Os filés de salga seca permaneceram em estufa por 48 horas e os submetidos a salga úmida permaneceu por 72 horas para secagem do produto. Sendo assim, todo o processo de salga seca durou 09 dias e para salga úmida 10 dias, considerando todo o processamento.

Para avaliar as condições higiênicosanitárias dos filés antes da salga e após o processamento, foram realizadas análises microbiológicas de Staphylococcus sp. coagulase positiva e Salmonella sp, segundo Silva et. al., (2001). Foi utilizada a técnica de Pour Plate (com os filés in natura $\mathrm{e}$ processados) para avaliação de unidades formadoras de colônia (UFC) dentro de 72 horas. A mesma técnica foi aplicada na matéria prima in natura, com 30 dias de estocagem e a última com 60 dias. Os filés foram estocados em sacos plásticos, separados por tratamento, em prateleiras de armário de alumínio, nas condições ambientes do laboratório.

No primeiro dia de estocagem, em 30 dias e em 60 dias de estocagem foram realizadas análises de atividade de água (aW), com a utilização de um Higrômetro Eletrônico de Fibra, e para análise de cor foi utilizado um equipamento espectrofotômetro de bancada para cor Colorquest II (Hunter Lab), com sistema de cor Cielab, calibrado previamente, operando com iluminante D65, ângulo $10^{\circ}$ no modo RSIN, no espaço CIE (Comission Internacionale de L'Eclairage) $\mathbf{L}^{*}, \mathbf{a}^{*}$, $\mathbf{b}^{*}$. Referente à análise de cor, temos:

- L: luminosidade (o máximo valor de L é 100, e representa uma perfeita reflexão difusa, enquanto que o valor mínimo é zero e constitui o preto.);

- a: intensidade da cor vermelha ("a" não apresenta limites numéricos específicos. Varia do vermelho " $+\mathrm{a}$ " ao verde "-a");

- b: intensidade da cor amarela ("b" não apresenta limites numéricos específicos. Varia do amarelo "+b" ao azul "-b"); - $\Delta \mathbf{E}$ : diferença total de cor. 
Segundo Scott (1997) a atividade de água (aW) é um dos fatores intrínsecos dos alimentos e é medida qualitativa que possibilita avaliar a disponibilidade de água livre que é susceptível a diversas reações. Assim, a quantidade de água livre que não se encontra comprometida com as moléculas constituintes do produto, esta disponível para as reações físicas, químicas $\mathrm{e}$ biológicas, tornando-se o principal responsável pela deterioração dos alimentos. No caso de um produto que apresente baixa atividade de água, há interrupção do metabolismo dos microorganismos presentes, inibindo o seu desenvolvimento ou reprodução (WELTI \& VERGARA, 1997).
Os dados obtidos foram submetidos a analise de variância e suas médias foram comparadas pelo teste de Tukey, ano nível de 5\% de significância.

\section{RESULTADOS E DISCUSSÃO}

Os resultados obtidos demonstram que as amostras manteram sua atividade de água abaixo do limite ótimo para desenvolvimento de microorganismos nas três análises, segundo BEAUCHAT (1981), garantindo assim o controle de patógenos por meio de atividade de água (Tabela 1.)

Tabela 1. Análise de atividade de água de filés de tambacu submetidos a salga seca e salga úmida, durante 60 dias de estocagem e valores mínimos para crescimento de patógenos de importância alimentar

\begin{tabular}{ccccc}
\hline \multicolumn{4}{c}{ Atividade de água $(\mathrm{aW})$} \\
\hline Dias de estocagem & Salga Seca & Salga úmida & $\begin{array}{c}\text { aW ideal para } \\
\text { crescimento } \\
\text { Salmonella } \text { sp. }\end{array}$ & $\begin{array}{c}\text { aW ideal para } \\
\text { crescimento } \\
\text { Staphylococcus } \text { sp. }\end{array}$ \\
\hline 0 & 0,59 & 0,60 & & 0,86 \\
30 & 0,56 & 0,58 & $0,92-0,95$ & \\
60 & 0,56 & 0,58 & & \\
\hline
\end{tabular}

Observando a atividade de água no dia 0 de estocagem nota-se que houve redução nos dois métodos de salga (seca e úmida) em relação aos dias de estocagem 30 e 60 , isso ocorre devido a redução da umidade por desidratação osmótica, princípio de conservação do $\mathrm{NaCl}$.

Segundo Aiura et al. (2008), avaliando o processo de salga úmida e seca em filés de pacu, a queda de umidade foi mais intensa e linear no processo de salga seca, atingindo aproximadamente $50 \%$ após 96 horas de salga. Nos resultados obtidos, conforme a (Tabela 1) verifica-se uma pequena elevação da atividade de água na salga úmida quando comparada a salga seca, sendo, portanto esta ultima a que apresenta maior penetração do sal e maior intensidade, visto que com a entrada do sal nas células há a saída de água da mesma.

Ribeiro et al. (2007) em análise da carne de Mapará (Hypophthalmus edentatus) desidratada osmoticamente e seca, os autores obtiveram valores de atividade de água de 0,78 para filés processados com $\mathrm{NaCl}$. E no presente trabalho, o maior valor de aW foi de 0,56 . 
Rev. Bras. Saúde Prod. Anim., Salvador, v.15, n.2, p.450-458 abr./jun., 2014 http://www.rbspa.ufba.br ISSN 15199940

Na Tabela 2 apresenta-se os resultados das análises microbiológicas do peixe in natura, indicando que as amostras encontram-se abaixo dos valores estabelecidos pela legislação (ANVISA, 2001), estando assim em condições higiênico-sanitárias satisfatórias, ou seja, apto para o consumo.

Tabela 2. Análise microbiológica dos filés In Natura

In Natura

\begin{tabular}{cccc} 
Staphylococcu sp. & ANVISA (Staphylococcus sp.) & Salmonella sp. & ANVISA (Salmonella sp.) \\
$0,1 \times 10^{2}$ & $5 \times 10^{2}$ & Aus & Aus \\
\hline
\end{tabular}

Na Tabela 3, estão os resultados microbiológicos dos filés após a salga seca e úmida, onde os resultados encontraram-se abaixo dos valores estabelecidos pela legislação (ANVISA, 2001) e não apresentaram diferença
$(\mathrm{P}>0,05)$ entre um tratamento e outro, indicando que para o peixe salgado seco e salgado em salmoura saturada estão em condições higiênico-sanitárias satisfatórias.

Tabela 3. Análise Microbiológica dos filés processados

\begin{tabular}{ccccc}
\hline \multicolumn{5}{c}{ Salga úmida } \\
\hline $\begin{array}{c}\text { Dias de } \\
\text { estocagem }\end{array}$ & Staphylococcus sp. & $\begin{array}{c}\text { ANVISA } \\
\text { (Staphylococcus } \text { sp. })\end{array}$ & Salmonella sp. & $\begin{array}{c}\text { ANVISA } \\
\text { (Salmonella } \text { sp. })\end{array}$ \\
\hline 0 & $1,1 \times 10^{2}$ a & $5 \times 10^{2}$ & Aus & Aus \\
30 & $1,3 \times 10^{2}$ a & $5 \times 10^{2}$ & Aus & Aus \\
60 & $1,9 \times 10^{2}$ a & $5 \times 10^{2}$ & Aus & Aus \\
\hline & & Salga Seca & Salmonella sp. & (Salmonella sp.) \\
\hline Dias de & Staphylococcus sp. & ANVISA & Aus & Aus \\
estocagem & $0,1 \times 10^{2}$ a & $5 \times 10^{2}$ & Aus & Aus \\
0 & $2,1 \times 10^{2}$ a & $5 \times 10^{2}$ & Aus & Aus \\
\hline 0 & $0,01 \times 10^{2}$ a & $5 \times 10^{2}$ &
\end{tabular}

Nível de significância teste de Tukey: $5 \%$; ${ }^{a}$ Representa igualdade entre as médias.

Segundo Furtado et al. (1991) algumas bactérias, leveduras e fungos são capazes de crescer em concentrações salinas elevadas. Franco (1996) descreve que bactérias do gênero Staphylococcus podem multiplicar-se em 7,5 a $15 \%$ de $\mathrm{NaCl}$. Dessa forma, a identificação do patógeno e o seu aumento no tratamento de 30 dias pode estar relacionada à limitação do efeito conservador do sal, ou ainda, deve-se provavelmente pelo pouco cuidado com a limpeza e desinfecção de superfícies ou por condições inadequadas na estocagem e conservação dos produtos (COSTA et al., 2008). Porém, com 60 dias de estocagem a quantidade de Staphylococcus diminuiu consideravelmente, provavelmente devido ao equilíbrio osmótico ainda não 
finalizado no processo, o que fez com que a concentração salina aumentasse paralisando a reprodução e / desenvolvimento dos microorganismos. De acordo com Bobbio \& Bobbio (1989) outra alteração que ocorre na carne de pescado durante a salga é a mudança de cor. A cor da carne e seus derivados é um importante aspecto de aceitabilidade do consumidor, dependente do estado químico do pigmento mioglobina (responsável pela cor vermelho púrpura). A coloração de um alimento deve-se à presença de pigmentos naturais. Estes pigmentos são instáveis e participam de diferentes reações. Em função disto, a alteração de cor de um alimento é um indicador das alterações químicas e bioquímicas possíveis de ocorrer durante $\mathrm{o}$ processamento e estocagem (RIBEIRO \& SERAVALLI, 2004).

A cor instrumental pode ser utilizada como parâmetro para estabelecimento de padrão de qualidade de um produto in natura ou processado (ALMEIDA, 1995; HUNG et al., 1995; GIMENO et al., 2000), ou ainda como fator de qualidade determinante da vida de prateleira de um produto, quando se estuda a sua variação com o tempo de estocagem (CHAI et al., 1991; KAJUNA et al., 1998; GONZÁLES et al., 1999).

Nas Figuras 1 e 2 podemos verificar que houve variação da coloração dos filés processados, tendo a maior diferença depois de 30 dias da salga. Isso pode estar relacionado ao equilíbrio osmótico ainda não finalizado no processo.

Segundo Ribeiro et al. (2007), quanto maior a porcentagem de Mioglobina e Hemoglobina na carne, mais escuro é o músculo do peixe. Como "L" (luminosidade) varia de branco (máximo) a preto (mínimo) pode-se afirmar que a amostra no dia 30 ficou mais escura, possivelmente devido à desnaturação que a proteína sofreu na presença de $\mathrm{NaCl}$.

Os dados de "a" (intensidade do vermelho) apresentaram pequena variação e, mostraram-se mais próximos do "verde", tendo pouca intensidade da coloração vermelha. Possivelmente é devido à menor quantidade de mioglobina presente no músculo, quando comparada à outras espécies animais. De acordo com Ramos et al.(2009), a falta de pigmentação nos músculos do peixe e aves é desejada pelo consumidor.

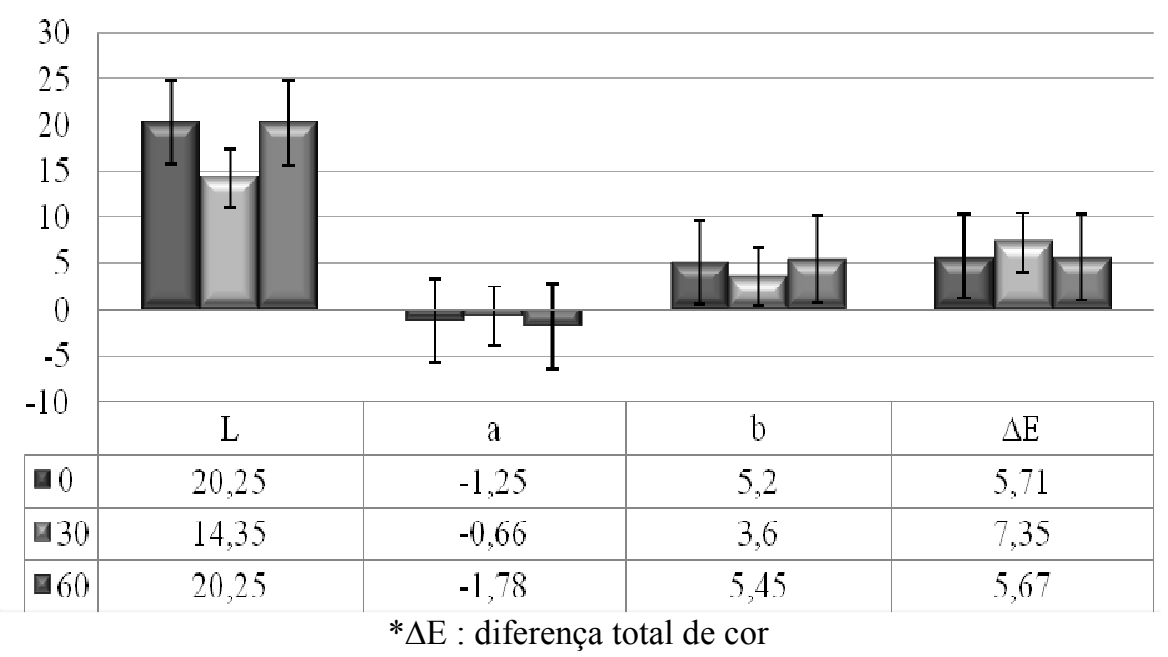

Figura 1. Análise de cor dos filés em salga seca 
Rev. Bras. Saúde Prod. Anim., Salvador, v.15, n.2, p.450-458 abr./jun., 2014 http://www.rbspa.ufba.br ISSN 15199940

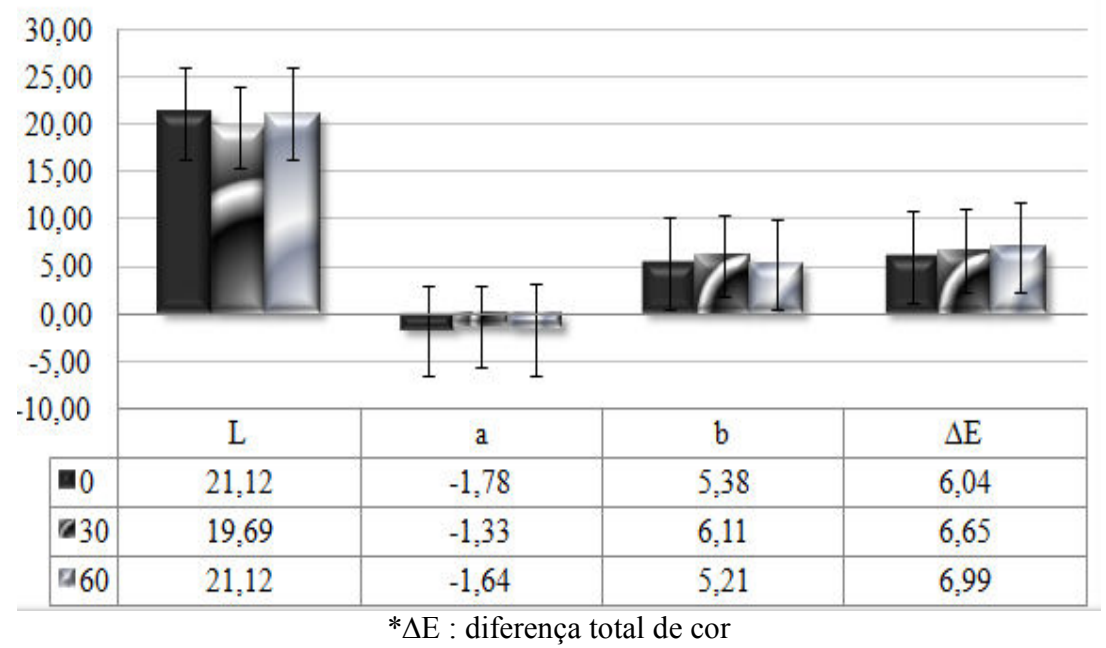

Figura 2. Análise de cor dos filés em salga úmida

Os dados de "b" (intensidade do amarelo) apresentaram variação diferenciada em relação aos diferentes tratamentos. Na salga seca, na análise do dia 30 houve uma redução da intensidade da cor amarela e, na salga úmida o efeito foi contrário, mostrando aumento de intensidade da cor amarela aos 30 dias com pequena diminuição aos 60 dias. Isto se deve possivelmente ao meio de solução em que foram dispostos os filés (meio seco e meio aquoso).

Dessa forma, os filés de Tambacus submetidos ao processo de salga seca e salga úmida avaliados em três tratamentos, mantiveram-se adequados com as exigências impostas pela legislação (ANVISA, 2001), possibilitando assim viabilizar sua comercialização, incentivo ao consumo e qualidade na vida de prateleira de produtos de pescados processados.

Portanto, os filés de Tambacu submetidos à salga seca e salga úmida apresentaram boas condições higiênicosanitárias, aptos para o consumo, baixa atividade de água e análise de cor satisfatórias, podendo ser utilizados para o desenvolvimento de novos processos tecnológicos de baixo custo, incentivando novas opções para o consumo de pescado no Brasil.

\section{REFERÊNCIAS}

AIURA, F.S.; CARVALHO, M.R.B.; VIEGAS, E.M.M.; KIRSCHNIK, P.G.; LIMA, T.M.A. Conservação de Filés de Tilápia do Nilos (Oreochromis niloticus) em salga seca e salga úmida.

Arquivo Brasileiro de Medicina Veterinária e Zootecnia, v.60, n.6, p.1531-1537, 2008.

\section{ALMEIDA, C. Determinação da firmeza e cor do tomate (Lycopersicum esculentum Mill) visando o estabelecimento de correlações entre medidas sensoriais e físicas ao longo do tempo de maturação. 1995. 102p. Dissertação (Mestrado em Tecnologia de Alimentos) - Universidade Estadual de Campinas, Campinas.}

AGÊNCIA NACIONAL DE VIGILÂNCIA SANITÁRIA ANVISA. Resolução RDC n⿳ 12, de 02 de janeiro de 2001. Disponível em: 
Rev. Bras. Saúde Prod. Anim., Salvador, v.15, n.2, p.450-458 abr./jun., 2014 http://www.rbspa.ufba.br ISSN 15199940

http://portal.anvisa.gov.br/wps/wcm/con nect/a47bab8047458b909541d53fbc4c6 735/RDC_12_2001.pdf?MOD=AJPER ES>. Acesso em: 3 nov. 2012.

BEAUCHAT, L.R. Microbial stability as affected by water activity. Cereal Food World, v.26, n.7, p.345-349, 1981.

BOBBIO, F.O.; BOBBIO, P.A. Introdução à química de Alimentos. São Paulo: Varela, 1989. p.191-221.

BOTELHO, A.T.; NORT, E. Pescado salgado no Brasil. Rio de Janeiro: Programa de Pesquisa e Desenvolvimento Pesqueiro no Brasil, 1972. 40p.

CARDOSO, J.M.B.A. A pesca como alternativa para $o$ desenvolvimento econômico do município de Calçoene, com implantação de um distrito industrial. 2003. 81p. Dissertação (Mestrado em Gestão Empresarial e de Negócios) - Faculdade de Macapá, Macapá.

CHAI, Y.L.; OTT, D.B.; CASH, J.N. Shelf life extension of Michigan Apples using sucrose polyester. Journal of Food Processing and Preservation, v.15, p.197-214, 1991.

FERREIRA, M.W.; SILVA, V.K.; BRESSAN, M.C.; FARIA, P.B.; VIEIRA, J.O.; ODA, S.H.I. Pescados processados: maior vida de prateleira e maior valor agregado. Lavras: Universidade Federal de Lavras, 2002. (Boletim de Extensão).

GIMENO, O.; ANSORENA, D.; ASTIASARÁN, I.; BELLO, J. Characterization of Chorizo de Pamplona: Instrumental Meansurements of Colour and Texture. Food Chemistry, v. 69, p.195-200, 2000.
GONZALES, A.P.; BURIN, L.; BUENA, M.P. Color changes during storage of honeys in relation to their composition and initial color. Food Research International, v.32, p.185191, 1999.

HUNG, Y.C.; MORITA, K.; SHEWFELT, R.; RESURRECCION, A.V.A.; PRUSSIA, S. Sensory and instrumental evaluation of apple color. Journal of Sensory Studies, v.10, p.15-23, 1995.

KAJUNA, S.T.A.R.; BILANSKI, W.K.; MITTAL, G.S. Color changes in bananas and plantains during storage. Journal of Food Processing and preservation, v.22, p.27-40, 1998.

LANDGRAF, M. Deterioração microbiana de alimentos. In: FRANCO, B. D. G. M.;

MARTINS, M.L.; MORAES, F.R.; FUJIMOTO, R.Y.; NOMURA, D.T.; FENERICK JUNIOR, J. Respostas do híbrido tambacú (Piaractus mesopotamicus HOLMBERG, 1887 macho X Colossoma macropomum CUVIER, 1818 fêmea) a estímulos simples ou consecutivos de captura. Boletim do Instituto de Pesca, v.28, n.2, p.195-204, 2002.

\section{NOGUCHI, E. Salted and dried} marine products in utilization of marine products. Tokyo: Overseas Technical Cooperation Agency, 1972. p.57-69.

OGAWA, M. O pescado como alimento. In: OGAWA, M; MAIA, E.L. Manual de Pesca, ciência e tecnologia de pescado. São Paulo: Varela, 1999. p.3-5. 
Rev. Bras. Saúde Prod. Anim., Salvador, v.15, n.2, p.450-458 abr./jun., 2014 http://www.rbspa.ufba.br ISSN 15199940

PEREZ, A.C.A.; AVDOLOV, N.; NEIVA, C.R.P.; LEMOS NETO, M.J.; LOPES, R.G.; TOMITA, R.Y.; FURLAN, É.F.; MACHADO, T.M.

Procedimentos higiênico-sanitários para a indústria e inspetores de pescado: recomendações. 2007.

Disponível

em: $<$ http://www.gipescado.com.br/arqu ivos/minsp.pdf $>$. Acesso em: 3 nov.

2012.

RAMOS, E.M.; GOMIDE, L.A.M. Avaliação da qualidade de carnes: fundamentos e metodologias. 22.ed. Viçosa, MG. Universidade Federal de Viçosa, 2009. p.242-243.

RIBEIRO, S.D.C.A.; RIBEIRO, C.D.F.A.; PARK, D.J.; ARAUJO, E.A.F.; TOBINAGA, S. Alteração da cor da carne de Mapará (Hypophthalmus edentatus) desidratada osmoticamente e seca. Revista

Brasileira de Produtos

Agroindustriais, v.9, n.2, p.125-135, 2007.
SCOTT, W.J. Water relation of food spoilage microorganisms. Advances in Food Research, v.7, p.83-127, 1957.

SOUZA, M.L.R. Comparação de seis métodos de filetagem, em relação ao rendimento de filé e de subprodutos do processamento da Tilápia-do-Nilo (Oreochromis niloticus). Revista Brasileira de Zootecnia, v.31, n.3, p.1076-1084, 2002.

WELTI, J.; VERGARA, F. Atividade de água / Conceito y aplicación em alimentos com alto contenido de humedad. In: AGUILERA, J.M. Temas em Tecnologia de Alimentos. Santiago de Chile: Universidad de Santiago de Chile, 1997. p.11-26.

Data de recebimento: 20/01/2014

Data de aprovação: 26/06/2014 